\title{
Gasification of spent pot-lining from the aluminum industry
}

\author{
Isam Janajreh ${ }^{1}$ (D) Sherien Elagroudy ${ }^{2} \cdot$ Chaouki Ghenai $^{3} \cdot$ Syed Shabbar Raza ${ }^{5} \cdot$ Idowu Adeyemi $^{1}$. \\ Konstantinos Moustakas ${ }^{4}$
}

Received: 25 March 2020 / Accepted: 16 February 2021 / Published online: 12 March 2021

(c) The Author(s) 2021 OPEN

\begin{abstract}
Aluminum production generates enormous spent pot lining (SPL) waste of around one million tons yearly, and these wastes are usually disposed in landfills. Hence, the technical feasibility of SPL gasification using both equilibrium and reactive high-fidelity modeling was evaluated in this study. Three SPL with different washing treatment, i.e., water (WWSPL), acid treated (ATSPL), and full treated (FTSPL, a combination of both water and acid washing) were used for the modeling. The equilibrium model considered twelve species, while the high-fidelity simulation was modeled with multiple species. Moreover, the high fidelity model is governed by the steady non-isothermal Navier-Stokes equation coupled with the discrete phase in Eulerian-Lagrangian scheme. The process metrics were assessed via the produced syngas fraction (CO/ $\mathrm{H}_{2}$ ) and gasification efficiency (GE). The equilibrium analysis of WWSPL, ATSPL, FTSPL, respectively, resulted in GE of 40, 65 , and $75 \%$. The corresponding syngas molar fractions for $\mathrm{CO}$ and $\mathrm{H}_{2}$ were 0.804 and 0.178 at $1450{ }^{\circ} \mathrm{C} ; 0.769$ and 0.159 at $1100^{\circ} \mathrm{C}$; and 0.730 and 0.218 at $1150^{\circ} \mathrm{C}$. These results suggest the potentiality and feasibility of gasifying the treated $\mathrm{SPL}$, which was considered in the high-fidelity. Although the results show different trend from equilibrium for the FTSPL gasification (i.e., small molar fraction of $\mathrm{CO}_{2}$ and $\mathrm{H}_{2} \mathrm{O}$ and high syngas fraction dominated by $\mathrm{CO}$ at 0.75 and $0.1 \mathrm{H}_{2}$ at best GE of 70\%), it re-emphasizes the potential of the gasification of FTSPL as recyclable/renewable energy source.
\end{abstract}

$\triangle$ Isam Janajreh, isam.janajreh@ku.ac.ae | ${ }^{1}$ Center for Membrane and Advanced Water Technology, Mechanical Engineering Department, Khalifa University of Science and Technology, Abu Dhabi, United Arab Emirates. ${ }^{2}$ Egypt Solid Waste Management Center of Excellence, Ain Shams University, Cairo, Egypt. ${ }^{3}$ Sustainable and Renewable Energy Department, Sharjeh University, Sharjah, United Arab Emirates. ${ }^{4}$ National Technical University of Athens, Athens, Greece. ${ }^{5}$ Department of Mechanical Engineering, Queensland University, Brisbane, Australia. 


\section{Graphical abstract}
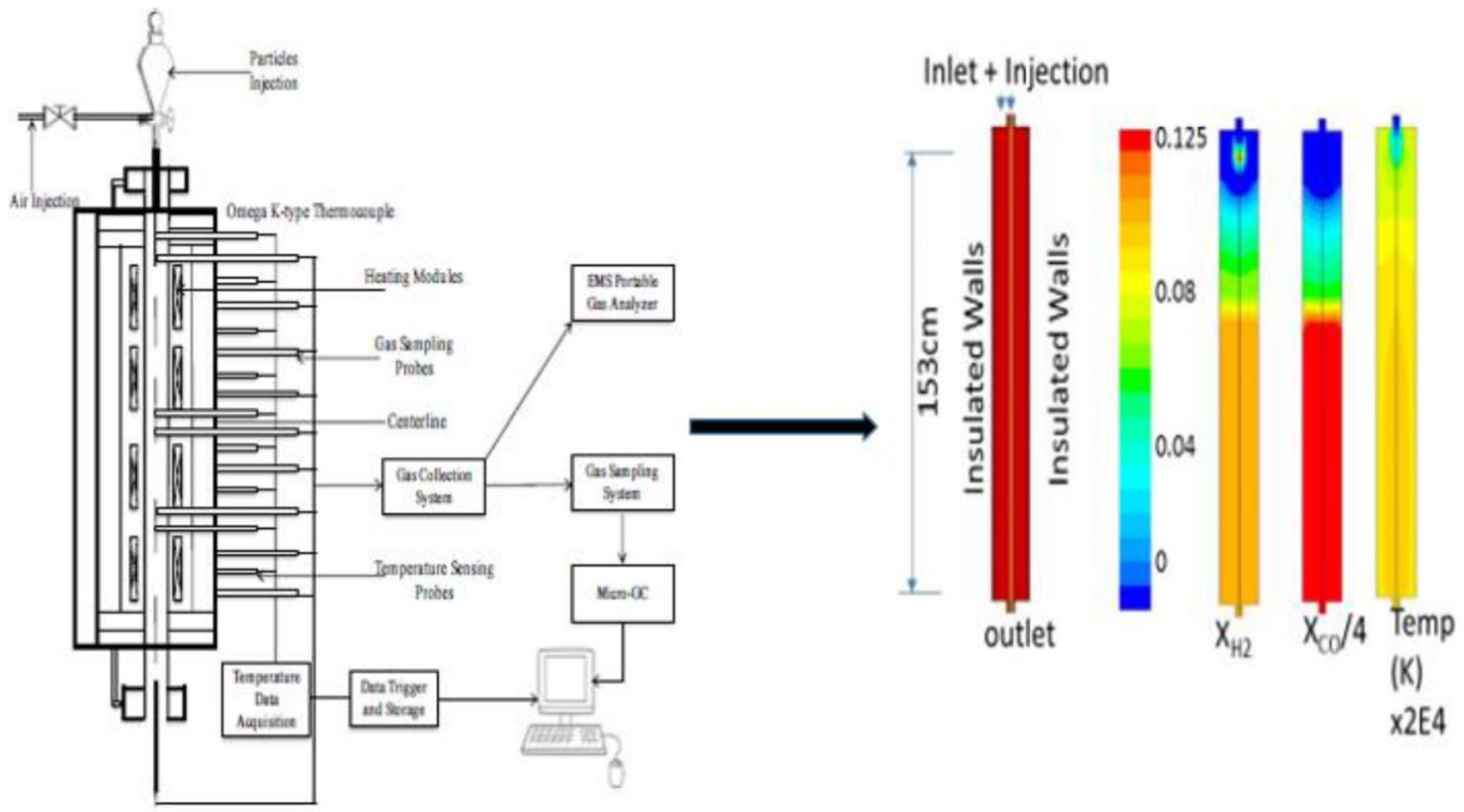

Keywords Spent pot lining · Aluminum waste - Gasification · Syngas - Equilibrium constant · Reactive flow

\section{Introduction}

The notion of reuse, recycle, and reduce is suited for almost all streams of solid waste; including municipal solid waste as well as many streams of industrial wastes. However, spent pot lining (SPL) is a poisonous and potentially explosive solid waste from aluminum industry that defies this general consensus, being hazardous to reuse, non-recyclable, and stockpiling over $1 \mathrm{Mt}$ annually [1, 2].
Aluminum industry produces a large amount of industrial solid waste such as the pre-baking anode electrolytic bath, its impermeable silicon carbide, the electrolyzed slag of the used cathode carbon block and the insulation side of the refractory brick [3]. These waste streams are on the rise due to the massively growing aluminum industry, and they are either illegally landfilled or stockpiled. In China, where $55 \%$ of the aluminum industry is located, an increase in SPL waste is reported to grow from $3.41 \mathrm{Mt}$ to $18.06 \mathrm{Mt}$
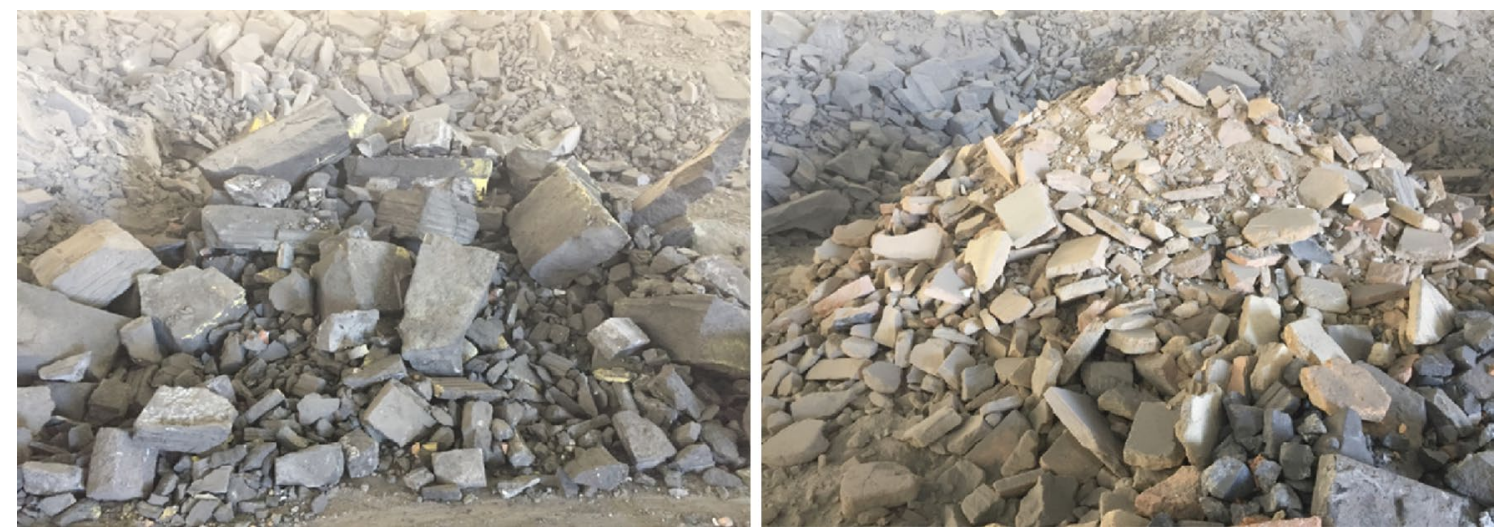

Fig. 1 The first SPL cut of carbonaceous grade (left) and the second SPL cut made of refractory, insulation bricks, and ramming paste (right) [29] 
over a ten-year period [4]. In aluminum production, alumina is converted to a pure metallic aluminum via electrolytic reduction known as Hall-Héroult process. In this process, an electrical current is applied to the carbon anode cell immersed in the electrolyte bath and passed down to the carbon cathode at the bottom of the cell. The electrolyte (consisting of alumina: $\mathrm{Al}_{2} \mathrm{O}_{3}$ and cryolite: $\mathrm{Na}_{3} \mathrm{AlF}_{6}$ ) is kept in liquid state owing to the high operational temperature which is near $960^{\circ} \mathrm{C}$ [5]. Over an operational period of 3 to 8 years, the cathode becomes polluted with fluoride salts and other process additives that halt its function. This mandates the removal of the carbon cathode potlining or SPL and re-lining the shell. It is estimated that the generated amount of the SPL is between 18 and $35 \mathrm{~kg}$ per ton of alumina; that mounts to nearly $1 \mathrm{Mt}$ annually $[6,7]$ with large amounts stockpiled.

This SPL waste stream can be easily separated into two sub-streams known as the first and second cuts as shown in Fig. 1. The 1st cut is a carbon-rich fraction, whereas the 2 nd cut is a non-carbonaceous part which consists of the old refractories $\left(\mathrm{SiO}_{2}\right.$ and $\left.\mathrm{Al}_{2} \mathrm{O}_{3}\right)$, insulating bricks, and ramming paste. The carbonaceous-rich 1 st cut has attracted interest as fuel substitute despite the presence of hazardous inorganic species $\left(\mathrm{Na}_{3} \mathrm{AlF}_{6}, \mathrm{NaF}, \mathrm{CaF}_{2}, \mathrm{Al}_{2} \mathrm{O}_{3}\right.$, and $\mathrm{NaAl}_{11} \mathrm{O}_{17}$, cyanide compounds, and soluble fluorides). The SPL is listed as hazardous waste by United States Environmental Protection Agency (EPA-D088 [1]). The cyanide has the propensity to form highly toxic hydrogen cyanide and caustic dissolved cyanides solution that result in the production of $\mathrm{H}_{2}$ and $\mathrm{CH}_{4}$, and risk explosions.

SPL reacts exothermally with water producing huge amounts of gases including $\mathrm{NH}_{3}, \mathrm{H}_{2}$, and $\mathrm{CH}_{4}$. A summary of the reaction chains is as follows:

$$
\begin{aligned}
& (\mathrm{SPL}: \mathrm{Al}, \mathrm{Na})+\frac{5}{2} \mathrm{H}_{2} \mathrm{O} \rightarrow 2 \mathrm{H}_{2}+\frac{1}{2} \mathrm{Al}_{2} \mathrm{O}_{3}+\frac{1}{2} \mathrm{NaOH} \\
& \mathrm{Al}+\mathrm{NaOH}+\mathrm{H}_{2} \mathrm{O} \rightarrow \frac{3}{2} \mathrm{H}_{2}+\mathrm{NaAlO}_{2}
\end{aligned}
$$

$\mathrm{Al}_{4} \mathrm{C}_{3}+6 \mathrm{H}_{2} \mathrm{O} \rightarrow 3 \mathrm{CH}_{4}+2 \mathrm{Al}_{2} \mathrm{O}_{3}$

$\mathrm{AlN}+3 \mathrm{H}_{2} \mathrm{O} \rightarrow \mathrm{NH}_{3}+\mathrm{Al}(\mathrm{OH})_{3}$

However, landfilling is the common practice for SPL management, claiming nearly $50 \%$ of the generated and untreated waste [8]. Hence, there are strong concerns of fluorides leaching (nearly 15\%) and emission of non-oxidized cyanides that have brought legislative interest in SPL detoxification and usage in other industries, as summarized in Table 1. Successful usage of the SPL in the cement industry has been reported [9-11], yet details on its potential as fuel substitute are still lacking. Additionally, the cement industry puts an upper limit to SPL usage amount of $0.2 \%$ by mass and restricts the inclusion of metal particles such as $A /$ which are damaging in the finished cement. Another concern is the long-term effect that has not been investigated by researcher. The steel industry is another gateway that can accommodate SPL as fuel and $\mathrm{CaF}_{2}$ substitutes where the latter helps in better formation of slags. Nevertheless, the amount of SPL that has been used in the steel industry is rather very small. In Australia, Regain Inc. detoxify SPL at the generation source after classification and crushing into inert and reactive streams [12]. The latter is hydrated based on the reactions listed in Eqs. (1)-(4) and the generated $\mathrm{H}_{2}$ and $\mathrm{CH}_{4}$ are partially used to destroy the cyanides leading to non-hazardous grade that can be accommodated by various industries, i.e., cement, steel, and brick or wall rock.

The 1st cut SPL was used as an auxiliary reducing agent by Von Krüger [13], tapping on its additional fluxing characteristics in ferro-silicon manganese smelting. More recently, 1st cut SPL was considered for gasification in a pilot scale plant where the destruction of cyanide and nearly $21 \%$ conversion was reported [14]. Plasma detoxification, and the subsequent production of energy and vitrified inert slag that could be safely landfilled, was reported by Tectonics group [15]. A claim of recycling $1^{\text {st }}$ cut SPL was reported also by ELkem who developed a process to crush and sieve SPL. And thereafter introduced
Table 1 Industrial use of untreated SPL [6]

\begin{tabular}{lll}
\hline Company & Industry & Location \\
\hline Albras-Aluar & Cement & Brazil \\
SELCA Tomago & Steel & Italy \\
Inespal, Hydro & Rockwool & Germany \\
RUSAL & Steel, cement (trials) & Bratsk \\
BHP Hillside, Bayside & Cement & South Africa \\
Sterlite Industries & Cement & Korba \\
Shandong, Guizhou aluminum smelter & Alumina plants & China \\
Hydro's process for Al/Si alloys & Aluminum industry & \\
\hline
\end{tabular}


the SPL with Quartz and Iron ore inside electric smelting furnace to produce reactive slag [8]. The reaction of the produced slag with the steam results in $\mathrm{AlF}_{3}$ which is a necessary electrolytic additive for the Hall-Héroult aluminum making process. The process energy cost, however, limits their deployment to full scale. Despite the progress made, industrial utilization for SPL is not deployed at a rate that manages this growing waste stream properly in view of the massively growing aluminum industry. This could be due to the lack of technical feasibilities for alternatives such as thermochemical pathways. Consequently, there is a clear need to manage this stream effectively.

One viable means to utilize waste streams such as SPL is through gasification [16]. Gasification is a thermochemical process whereby a feedstock, that is usually rich in carbon, reacts with lean oxygen or air to produce synthetic gases (syngas) which is composed of mainly carbon monoxide and hydrogen [17]. The syngas is then used for power generation, fuel production or chemical synthesis after a cleanup to remove $\mathrm{S}, \mathrm{NOx}, \mathrm{Cl} 2, \mathrm{Hg}$, etc. The utilization in power production often occurs through a combined cycle known as Integrated Gasification Combined Cycle (IGCC). Through the usage of IGCC, an enhanced efficiency could be attained with a combination of gas and steam turbines, and clean conversion of the feedstock could be achieved through precombustion capture [18-20]. Entrained flow gasification (EFG) is the main technology used in IGCC due its many benefits [21, 22]. EFG has high gasification efficiency, char conversion and produces little to no tar. Hence, there are seven different entrained flow gasification technologies currently in commercial operation, namely Hitachi, E-Gas, Babcock Borsig Power (BBP), Shell Coal Gasification Process (SCGP), Texaco (now GE), Mitsubishi Heavy Industries (MHI) and Prenflo. EFGs operate at high temperatures, 1250-2200 K, in order to achieve better conversion [23]. Besides the use for power production, the syngas from gasification can be used in the synthesis of chemicals, production of transportation hydrocarbon-based fuels from Fischer-Tropsch or methanol to gasoline (MTG) conversion of the syngas in appropriate stoichiometry, formation of fertilizer, generation of electricity through the utilization of hydrogen in syngas in fuel cells amongst other benefits.

This work attempts to assess the conversion of SPL into an added value syngas through gasification. To evaluate this multiphase reaction process, equilibrium based as well as high fidelity computational fluid dynamics were pursued. The two models provide a macro- and micro-scale details to the gasification. To our knowledge, there are no rigorous gasification investigations in the literature that focus on SPL. Gasification modeling studies have focused on coal and biomass feedstock. Furthermore, results were mostly limited to laboratory scale or pilot studies. For example, Brown et al. obtained temperature and syngas composition for several types of coal in their oxy gasification laboratory scale gasifier at Brigham-Young University by Brown et al. [24], and Hill and Smooth [25] developed high fidelity CFD gasification simulation that mimic the measurements of BYU gasifier. In the year to follow, two-stage pilot scale gasifier was built by Mitsubishi industries that is fed by coal at 200 tons/ day. Measurements and the development of high fidelity simulations and comparisons appeared in the work of Chen et al. [26, 27] and Watanabe and Otaka [28]. From the above, gasification modeling was done to evaluate process metrics, including species, temperature, and flow distributions, as well as the extent of reaction. This provides a tool to conduct sensitivity study aid in the evaluation of the process efficiency up to the reactor design stage. There are two levels of modeling: one that is based on Gibbs energy minimization or equilibrium based and is referred as systematic and another that is based on high fidelity of coupled flow reaction kinetics of non-isothermal, turbulent, and multiple species flow. This work utilized these two approaches in an attempt to provide the needed assessment of the SPL conversion.

\section{Methodology}

The low fidelity and high fidelity analysis were conducted in order to evaluate the feasibility of the gasification of the SPL. The material characterization of the SPL through proximate, ultimate, and heating value analysis was acquired from a previous study [29] prior to the modeling as they are essential to their proper predictions.

\subsection{Material characterization}

The material characterization, which includes the proximate, ultimate and heating value analysis, was obtained from our previous study on SPL [29]. The proximate analysis was conducted with TA Instruments' DSC/TGA Q600, the ultimate analysis was performed with Thermo-Scientific Flash 2000 CHNOS (TCD), and the heating value was determined with Parr 6100 bomb calorimeter.

\subsection{Low fidelity gasification modeling}

The assumption of equilibrium is amenable to high temperature gasification, and specifically in entrained flow gasification (EFG), than the lower temperature gasification systems such as fixed bed, moving bed, and fluidized bed technologies [30-33]. EFG technology is popular and used by BBP, Hitachi, MHI, Prenflo, SCGP, E-Gas, and Texaco with the advantage of lower tar, $\mathrm{CO}_{2}$, and $\mathrm{CH}_{4}$ and superior 


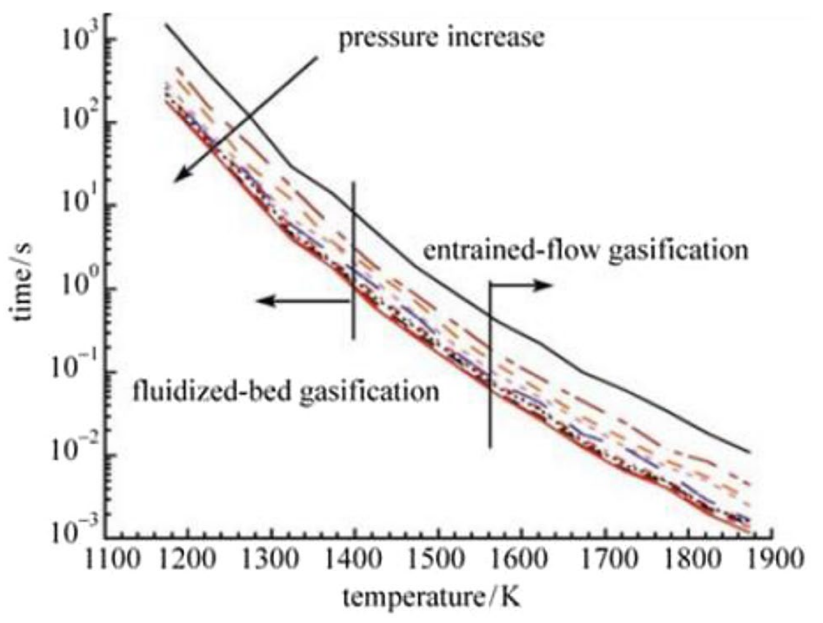

Fig. 2 Reaction equilibrium time scale in function of temperature as well as pressure of the gasifier [34]

flexibility of feedstock over other systems, but at the price of smaller particle size requirements. The feedstock is typically crushed and pulverized to ensure its complete carbon conversion. It can be admitted as wet-slurry or dry-solid into the EFG. The EFG can also be of two types, i.e., nonslagging or slagging, depending on downstream plan for bottoming ash further treatment and usage or for safe disposal as vitrified stable minerals.

The high temperature environment of EFG makes equilibrium modeling more feasible for EFG over other gasification systems, and this has been observed by some studies. For example, Wang et al. [34] (Fig. 2) illustrated the reaction time scale inside the gasifier and its dependency on the operation pressure and temperature that suggested the position of equilibrium which falls within the range of operation of the EFG temperature range [34].

At the condition of the EFGs, the time of the reactions is greatly reduced to be safely considered to be in the equilibrium operation range. For instance, when operating the EFG at $1300^{\circ} \mathrm{C}$, the reaction time for the production of syngas was about $0.1 \mathrm{~s}$ which is essentially less than the average residence time inside the gasifier, i.e., in the order of several seconds [34]. Therefore, equilibrium modeling of
EFGs is justifiable at their operational temperature. Moreover, it could be inferred from the study of Wang et al. [34] that there is pronounced influence of the temperature over the pressure.

In general, there are two main approaches for developing a gasification model, i) the Equilibrium constant method (ECM) and ii) the Element potential method (EPM). In this work, we considered the ECM which has been reported in several works $[35,36]$. These models apply elemental balance, methanation reaction, water-gas shift (WGS) reaction, Boudouard reaction, and energy balance. They were simple to code and easily understood in determining the equilibrium species concentrations, and the temperature and pressure products conditions [31]. The main assumption was that the process takes infinite residence time under chemical and thermodynamic equilibrium $[37,38]$. For that, reaction kinetics were neglected and no intermediate species was accounted for as the model lacked the concept of time, mixing and geometry to provide spatial distribution of species. Nevertheless, the gasifier metrics such as GE and conversion under best case scenario were evaluated. Practically, the operation was subjected to heat losses, kinetic limitations, localized flow turbulence and variation in spatial and temporal species distribution, yielding lower efficiencies than the equilibrium assumption. During gasification of hydrocarbons, oxygen is depleted in a series of heterogeneous and homogeneous reactions as summarized in Table 2. Therefore, R1 through R3 reactions do not contribute to the equilibrium composition, and only the last three reactions were considered during equilibrium. In these reactions, the solid carbon feedstock is consumed and the products are limited to $\mathrm{CO}, \mathrm{CO}_{2}, \mathrm{CH}_{4}, \mathrm{H}_{2}, \mathrm{H}_{2} \mathrm{O}$, and Ash.

Additionally, the traces of Nitrogen and Sulfur and the formation of $\mathrm{N}_{2}, \mathrm{NH}_{3}, \mathrm{COS}$, and $\mathrm{H}_{2} \mathrm{~S}$ were considered simultaneously. The objective was to solve for these 10 species as well as oxygen ratio per feedstock, and steam ratio per feedstock during gasification at a specified temperature and pressure. Therefore, a total of 12 unknowns were generated, governed by 12 equations; the five elemental balance of each of $\mathrm{C}, \mathrm{O}, \mathrm{H}, \mathrm{N}$, and $\mathrm{S}$, the one total
Table 2 Gasification reaction of the main species and their corresponding heat of reactions

\begin{tabular}{llll}
\hline Reaction\# & Reaction stoichiometry & $\begin{array}{l}\text { Reaction energy } \\
(\mathrm{MJ} / \mathrm{kmol})\end{array}$ & Description \\
\hline R1 & $\mathrm{C}+\frac{1}{2} \mathrm{O}_{2} \rightarrow \mathrm{CO}$ & -111 & Carbon combustion reaction \\
R2 & $\mathrm{CO}+\frac{1}{2} \mathrm{O}_{2} \rightarrow \mathrm{CO}_{2}$ & -283 & CO combustion \\
R3 & $\mathrm{H}_{2}+\frac{1}{2} \mathrm{O}_{2} \rightarrow \mathrm{H}_{2} \mathrm{O}$ & -242 & $\mathrm{H}_{2}$ combustion \\
R4 & $\mathrm{C}+\mathrm{H}_{2} \mathrm{O} \leftrightarrow \mathrm{CO}+\mathrm{H}_{2}$ & +131 & Steam gasification, reforming \\
R5 & $\mathrm{C}+\mathrm{CO}_{2} \leftrightarrow 2 \mathrm{CO}$ & +173 & Boudouard reaction \\
R6 & $\mathrm{C}+2 \mathrm{H}_{2} \leftrightarrow \mathrm{CH}_{4}$ & -75 & Methanation reaction \\
\hline
\end{tabular}


heat balance, the three equilibrium reaction of Water-gas (R4), Boudouard (R5), and Methanation (R6), and, finally, the three formation of $\mathrm{NH}_{3}, \mathrm{COS}$, and $\mathrm{H}_{2} \mathrm{~S}$. Each of above reaction equations is independent and has an associated equilibrium equation in terms the Arrhenius concentration $K_{\mathrm{c}}$ or the partial pressure $K_{\mathrm{p}}$ as follows:

$K_{\mathrm{c}}(T)=\frac{[C]^{c}[D]^{d}}{[A]^{a}[B]^{b}} \quad$ or $K_{\mathrm{p}}(T)=\frac{p_{C}^{c} \cdot p_{D}^{d}}{p_{A}^{a} \cdot p_{B}^{b}}$

where

$K_{\mathrm{c}}(T)=K_{\mathrm{p}}(T) \cdot(R T)^{c+d-a-b}$

$k_{c}(T)=A_{r} T^{\beta_{r}} e^{-\frac{E_{r}}{R T}}$

$[X]$ representing the molar concentration of species $X$, $A$ is the pre-exponent constant, $\beta$ is temperature exponent constant, $E_{r}$ is the activation energy which is quoted to the Gibbs free energy of the reaction, $R$ is the universal gas constant $(R=8.313 \mathrm{~kJ} / \mathrm{kmol} \mathrm{K}), T$ is the reaction absolute temperature. The steady form of the energy equation is written as:

$\sum_{i=1}^{n \text { product }} \dot{n}_{i} h_{i}=\sum_{i=1}^{n \text { reactant }} \dot{n}_{i} h_{i}+\dot{Q}$

where $n$ is the number of moles and the dot indicates time rate. $h$ is the enthalpy term and includes the formation and sensible enthalpies. The 9 species $\left(\chi_{\mathrm{CO}_{2}}, \chi_{\mathrm{CO}}, \chi_{\mathrm{H}_{2}}, \chi_{\mathrm{CH}_{4}}\right.$, $\chi_{\mathrm{N}_{2}}, \chi_{\mathrm{NH}_{3}}, \chi_{\mathrm{H}_{2} \mathrm{~S}}, \chi_{\mathrm{COS}}, \chi_{\mathrm{H}_{2} \mathrm{O}}$ oxygen ratio per feedstock, and steam ratio per feedstock) can be solved iteratively. The feedstock is defined according to its proximate and ultimate composition in addition to its lower heating value as shown in Table 2, leading to the evaluation of the molar or mass fractions of each as well as the moderator steam and oxidizer molar ratio to that of the feedstock. The baseline coal is common bituminous grade. The analyses were carried out at a fixed pressure of 30 bars and at sweeping values of temperature between 750 and $1550^{\circ} \mathrm{C}$. Additional to species distribution, the cold gasification efficiency (GE) had been evaluated without accounting for any of the product sensible heat. GE is defined as the ratio of the yield syngas accumulative heating value to the measured SPL heating value with any extra heat.

\subsection{High fidelity reactive flow modeling}

The major limitation of systematic analysis is the absent of gasifier geometry and reaction kinetics. These are related as the dynamics of the fluid influence its reactivity and its kinetics. A high-fidelity reaction flow simulation can
Table 3 Model dimensions and condition of the baseline coal and treated SPL

\begin{tabular}{|c|c|c|}
\hline Condition & Baseline & Injector (FTSPL) \\
\hline \multicolumn{3}{|l|}{ Oxidizer stream } \\
\hline Flow rate $(\mathrm{kg} / \mathrm{s})$ & 0.0062223 & 0.0056321 \\
\hline \multicolumn{3}{|c|}{ Component mole fraction } \\
\hline $\mathrm{O}_{2}$ & 0.8 & 0.8 \\
\hline $\mathrm{N}_{2}$ & 0.2 & 0.2 \\
\hline Temperature $\left({ }^{\circ} \mathrm{C}\right)$ & 94 & 94 \\
\hline Wall & Adiabatic $\frac{\mathrm{d} T}{\mathrm{~d} x}=0$ & - \\
\hline
\end{tabular}

overcome this limitation in using reactive Navier-Stokes flow. The reaction kinetics has been evaluated in priori using thermo-gravimetric analysis based on previous studies [30, 39]. The cylindrical geometry of the gasifier was modeled using axi-symmetric and discretized using finite volume code. The transport equations were solved using the segregated implicit solver in a steady state solution. The undertaking geometry is the drop tube reactor that appears in the authors work [40] that was initially subjected to surface heating to start the conversion and then left to run allothermally. This geometry is also similar to the one considered in the work of Albani and Ghoniem [41]. Table 3 provides the basic geometrical detail of the drop tube gasifier as well as the discretized mesh. A structural multi-blocking mesh discretization was used for the cylindrical drop tube geometry radius $6.5 \mathrm{~cm}$ and height $150 \mathrm{~cm}$, and it resulted in 53,155 rectangular mesh as a baseline. The grid was refined near the steep flow gradient zone, i.e., near the air nozzle outlet, walls, combustion, and reduction zone to capture the highly turbulent flow. The no-slip and no-flow boundary conditions were imposed on the gasifier wall. The solid phase (coal or SPL) particles were injected with the oxidizer stream at the inlet which is located at the top of the reactor. A non-uniform distribution model was used to represent the spherical discrete particle form. The gasifier was divided into top, middle, and bottom section in which only the middle suction is heated and kept at constant temperature, while the top and bottom were maintained at much lower temperature, i.e., without heating. The turbulence is accounted for using $\mathrm{k}-\varepsilon$ model with standard wall function to avoid boundary layer over-refinements, using a practical mesh size. The SIMPLE algorithm and second-order discretization scheme were used to calculate velocity-pressure coupling and all other variables. A residual of $1 \mathrm{e}-5$ is used for minimum convergence criteria for all transport equations.

The two-phase flow was modeled separately using the Lagrangian and Eulerian approach for the discrete solid and continuous fluid, respectively. The baseline coal and SPL particles were modeled as discrete solid, while oxygen and gaseous species were considered as the continuous 
fluid. The formulation holds best to describe the surface heterogeneous reactions as well as volumetric homogeneous reactions for the multiple reaction species. The following transport equation is used as the governing equation for the continuous flow,

$\frac{\partial}{\partial t}(\varphi)+\frac{\partial}{\partial x_{i}}\left(u_{i} \varphi\right)=-\frac{\partial}{\partial x_{i}}\left(\Gamma_{\varphi} \frac{\partial \varphi}{\partial x_{i}}\right)+S_{\varphi}$

where $S_{\phi}$ is source-terms representing the discrete phase connection, $\phi$ representing the density $(\rho), t$ is the time, $u_{i}$ is the velocity component to represents turbulent scalars, i.e., two separate equations for turbulent kinetic energy $(k)$ and dissipation rate $(\varepsilon)$ are given below. The steady state flow regime for these two transport equations given below:

$\rho u_{i} \frac{\partial k}{\partial x_{i}}=\mu_{t}\left(\frac{\partial u_{j}}{\partial x_{i}}+\frac{\partial u_{i}}{\partial x_{j}}\right) \frac{\partial u_{j}}{\partial x_{i}}+-\frac{\partial}{\partial x_{i}}\left(\frac{\mu_{t}}{\sigma_{k}} \frac{\partial k}{\partial x_{i}}\right)-\rho \varepsilon$

$\rho u_{i} \frac{\partial \varepsilon}{\partial x_{i}}=C_{1 \varepsilon} \frac{\mu_{t} \varepsilon}{k}\left(\frac{\partial u_{j}}{\partial x_{i}}+\frac{\partial u_{i}}{\partial x_{j}}\right) \frac{\partial u_{j}}{\partial x_{i}}+\frac{\partial}{\partial x_{i}}\left(\frac{\mu_{t}}{\sigma_{\varepsilon}} \frac{\partial \varepsilon}{\partial x_{i}}\right)-C_{2 \varepsilon} \frac{\rho \varepsilon^{2}}{k}$

The generation, the diffusion, and the destruction, respectively, are given on the right-hand side. The $\mu_{\mathrm{t}}$ represents the turbulent/eddy viscosity and given as

$\mu_{t}=f_{\mu} C_{\mu} \rho k^{2} / \varepsilon$

where $f, C, C_{1 \varepsilon^{\prime}} C_{1 \varepsilon^{\prime}} \sigma_{k^{\prime}}$ and $\sigma_{\varepsilon}$ are the constants that can be taken from the literature.

The species $\left(m_{i}\right)$ mass transport equation is given as:

$\frac{\partial}{\partial t}\left(\rho m_{i}\right)+\frac{\partial}{\partial x_{i}}\left(\rho u_{i} m_{i}\right)=\frac{\partial}{\partial x_{i}}\left(\rho D_{i, m}+\mu_{t} / S c_{t}\right) \frac{\partial m_{i}}{\partial x_{i}}+R_{i}+S_{i}$

where $S c_{t}$ is the turbulent Schmidt number, $D_{i, m}$ is the diffusion coefficient, $R_{i}$ is the homogeneous reaction source, $S_{i}$ is the discrete phase reaction source. The following equation shows the stoichiometric reaction for the reactions listed in Table 4 with the Arrhenius kinetic parameters,

$$
\sum_{i=1}^{N} v_{i, r}^{\prime} S_{i} \underset{b_{b, r}}{\stackrel{k_{f, r}}{\Leftrightarrow}} \sum_{i=1}^{N} v_{i, r}^{\prime \prime} S_{i}
$$

The finite rate/eddy dissipation model was employed to define the relationship between chemistry and turbulence to deal with gas-phase and solid particle reactions.

The two-way coupling mechanism of the cloud-model [42] was used to account for momentum, heat, and mass transfer between discrete and gas phases. This was achieved by tracking a cloud of particles about a mean trajectory which was calculated by solving the equation of motion for all particle by the ensemble-averaged method. The ith species production/destruction due to the reaction $r$ followed either instantaneous eddy dissipation model [Eq. (7)] or the finite rate model [Eqs. (8) and $(9 a, b)]$.

$R_{i, r}=v_{i, r}^{\prime} M_{i} A \rho \frac{\varepsilon}{\kappa} \min _{R}\left(Y_{R} / v_{R, r} M_{R}\right)$

where $A$ is constant and $Y$ is the mass fraction of reaction species;

$\hat{R}_{i, r}=\Gamma\left(v_{i, r}^{\prime \prime}-v_{i, r}^{\prime}\right)\left(k_{f} \prod_{j=1}^{N} C_{j, r}^{v_{, j}^{*}}-k_{b} \prod_{j=1}^{N} C_{j, r}^{v_{j, r}^{\prime *}}\right)$

and

$R_{i}=M_{i} \sum_{r=1}^{n} \hat{R}_{i, r}$

where $\Gamma$ is the net effect of third bodies on the reaction rate, $k$ is the Arrhenius reaction constant, $[C]_{j}$ is the molar concentration of $j$ th species raised to stoichiometric coefficients $v$ and reaction order $\eta, M_{i}$ is the molecular weight of species $i$.

The heterogeneous surface reaction for the solid char discrete particles with the oxidizer to form $\mathrm{CO}$ or $\mathrm{CO}_{2}$ is given by,

$\bar{R}_{i, r}=A \eta_{r} Y_{r} R_{j, r}$
Table 4 The main reactions and their kinetics for high fidelity analysis [47]

\begin{tabular}{llll}
\hline Reaction & & Kinetic parameters $A_{\mathrm{j}}, E_{\mathrm{j}}[\mathrm{kJ} / \mathrm{mol}]$ & Reaction type \\
\hline R1 & $2 \mathrm{CO}+\mathrm{O}_{2} \rightarrow 2 \mathrm{CO}_{2}$ & $\left.A=10^{17.6}\left[\mathrm{~m}^{3} \mathrm{~mol}^{-1}\right)^{-0.75} \mathrm{~s}^{-1}\right], E=166.28$ & Exothermic \\
R2 & $2 \mathrm{H}_{2}+\mathrm{O}_{2} \rightarrow 2 \mathrm{H}_{2} \mathrm{O}$ & $A=10^{11}\left[\mathrm{~m}^{3} \mathrm{~mol}^{-1} \mathrm{~s}^{-1}\right], E=42$ & Exothermic \\
R3 & $\mathrm{CO}+\mathrm{H}_{2} \mathrm{O} \leftrightarrow \mathrm{CO}_{2}+\mathrm{H}_{2}$ & $A=0.0265, E=65.8$ & Exothermic \\
R4 & $\mathrm{C}_{(\mathrm{s})}+\mathrm{O}_{2} \rightarrow \mathrm{CO}_{2}$ & $A=5.67 e 9\left[\mathrm{~s}^{-1}\right], E=160$ & Exothermic \\
R5 & $\mathrm{C}_{(\mathrm{s})}+\mathrm{CO}_{2} \rightarrow 2 \mathrm{CO}$ & $A=7.92 e 4\left[\mathrm{~m}^{3} \mathrm{~mol}^{-1} \mathrm{~s}^{-1}\right], E=218$ & Endothermic \\
R6 & $\mathrm{C}_{(\mathrm{s})}+2 \mathrm{H}_{2} \rightarrow \mathrm{CH}_{4}$ & $A=79.2\left[\mathrm{~m}^{3} \mathrm{~mol}^{-1} \mathrm{~s}^{-1}\right], E=218$ & Exothermic \\
R7 & $\mathrm{C}_{(\mathrm{S})}+\mathrm{H}_{2} \mathrm{O} \rightarrow \mathrm{CO}+\mathrm{H}_{2}$ & $A=7.92 e 4\left[\mathrm{~m}^{3} \mathrm{~mol}^{-1} \mathrm{~s}^{-1}\right], E=218$ & Endothermic \\
R8 & $\mathrm{vol}+0.4 \mathrm{O}_{2} \rightarrow 1.317 \mathrm{CO}+2.09 \mathrm{H}_{2}+0.064 \mathrm{~N}_{2}$ & $A=1 e 15\left[\mathrm{~m}^{3} \mathrm{~mol}^{-1} \mathrm{~s}^{-1}\right], E=1 E 8$ & Exothermic \\
\hline
\end{tabular}


with

$R_{i, r}=K_{k i n, r c}\left[p_{j}-R_{i, r} / D_{o, r}\right]^{N r}$

where $A$ here is the particle surface area, $\eta$ is the effective factor, $Y_{i}$ is the mass fraction of species $i, r$ is the rate of reaction, $K$ is the kinetic rate of reaction, and $P$ is the bulk partial pressure of the species $i, D$ is the diffusion rate coefficient for reaction $r$ and $\mathrm{N}$ is apparent order of the reaction $r$. The discrete solid particle phase was solved in a Lagrangian frame of reference by equating the particle inertia with the forces acting on the particle and can be described as:

$\frac{d \vec{u}_{P}}{d t}=F_{D}\left(\vec{u}-\vec{u}_{P}\right)+\vec{g}\left(\rho_{P}-\rho\right) / \rho_{P}$

where $F_{D}\left(u-u_{p}\right)$ is the drag force per unit particle mass; $u$ is the fluid phase velocity; $u_{p}$ is the particle velocity; $\rho$ is the fluid density, and $\rho_{p}$ is the density of the particle.

The stepwise integration over discrete time steps was used to solve the trajectory equation in which the velocity of the particle was computed at each point by integration, using the trajectory predicted by the following equation,

$\frac{d x}{d t}=u_{P}$

Equations similar to (12) and (13) were solved for each coordinate direction to predict the trajectories of the discrete phase. At vaporization temperature $\left(T_{\text {vap }}\right)$, the devolatilization law activated for the combustible particle mass $\left(m_{p}\right)$ according to the following equation,

$-\frac{d m_{p}}{d t}=A e^{-(E / R T)}\left[m_{p}-\left(1-f_{v}^{0}\right) m_{p}^{0}\right]$

where $f_{v}$, and $m_{p}{ }^{\circ}$ are the volatile fraction and initial mass, respectively. It remains in effect, while the mass of the particle, $m_{p}$, exceeds the mass of the non-volatiles in the particle. The governing equation for the conductive, convective, and radiative heat transfer to the particle during devolatilization is written as, $m_{p} c_{p} \frac{d T_{p}}{d t}=h A_{p}\left(T_{\infty}-T_{p}\right)+\frac{d m_{p}}{d t} h_{f g}+\varepsilon_{p} A_{p} \sigma\left(T_{R}^{4}-T_{p}^{4}\right)$

where $c_{p}, h_{f g}$ A, and $\sigma$ are specific heat, latent heat of evaporation, particle surface area, and Stefan constant, respectively. Once the particle volatile component is evolved, a surface reaction begins until the combustible fraction is consumed. The proximate analysis, ultimate analysis, and heating value from Table 2 were used to define the composition of SPL into the software, i.e., ANSYS/Fluent.

\section{Results and discussion}

\subsection{Material characterization}

Gasification is suited for coal, biomass, and other streams of solid waste based on consideration of the fixed carbon as well as the volatile contents of the candidate feedstock. This is revealed through well-established material characterization which would infer the proximate and ultimate composition of the feedstock. Proximate analysis reveals the four main fractions of the materials, i.e., moisture, volatile, fixed carbon or char, and minerals or ash. Ultimate analysis, on the other hand, provides the essential elemental compositions including $\mathrm{C}, \mathrm{H}, \mathrm{N}, \mathrm{S}$, and $\mathrm{O}$. These analyses were conducted using specialized analytical equipment such as Thermo-Gravimetric Analyzer (TGA), CHNSO Elemental Analyzer, and bomb calorimetry that measures the heating/calorific value of the feedstock. Either XRF or inductively coupled plasma (ICP) can be used, respectively, for macro- and trace elemental analyses of the mineral/ ash. From these analysis, one can infer the unit molecular formula based on a single carbon atom in the form of $\mathrm{CH}_{\mathrm{x}} \mathrm{O}_{\mathrm{y}} \mathrm{N}_{z} \mathrm{~S}_{z}$ or simply mark the material on the van-Krevelen diagram $(\mathrm{O} / \mathrm{C}$ vs $\mathrm{H} / \mathrm{C})$ that can be directly compared to different grades of coal, biomass, lignite, etc.

The issue with SPL is extracting representative and homogenized samples. That can be done by obtaining large chunks of $15 \mathrm{~kg}$ total mass, crushing, and sieving to

Table 5 Proximate and ultimate analysis (weight \%) and measured calorific values and inferred molecular formulas [29]

\begin{tabular}{lllllllllllll}
\hline Feedstock & MC (\%) & VM (\%) & FC (\%) & Ash (\%) $\begin{array}{l}\text { Calorific } \\
\text { value (MJ/ } \\
\text { kg) }\end{array}$ & C (\%) & O (\%) & $\mathrm{H}(\%)$ & $\mathrm{N}(\%)$ & $\mathrm{S}(\%)$ & Unit formula \\
\hline RSPL & 3.46 & 6.18 & 38.96 & 51.4 & 12.1 & 42.19 & 55.36 & 0.62 & 0.59 & 1.24 & $\mathrm{CH}_{0.168} \mathrm{O}_{0.984} \mathrm{~N}_{0.012} \mathrm{~S}_{0.011}$ \\
WWSPL & 2.4 & 5.91 & 40.37 & 51.32 & 16.4 & 48.08 & 49.59 & 0.21 & 0.4 & 1.72 & $\mathrm{CH}_{0.051} \mathrm{O}_{0.774} \mathrm{~N}_{00.07} \mathrm{~S}_{0.013}$ \\
ATSPL & 2.2 & 4.78 & 67.77 & 25.25 & 21.2 & 72.01 & 24.83 & 0.15 & 0.55 & 2.46 & $\mathrm{CH}_{0.025} \mathrm{O}_{0.259} \mathrm{~N}_{0.007} \mathrm{~S}_{0.013}$ \\
FTSPL & 2.1 & 0.2 & 82.86 & 14.84 & 28.0 & 87.03 & 9.45 & 0.21 & 0.64 & 2.67 & $\mathrm{CH}_{0.028} \mathrm{O}_{0.081} \mathrm{~N}_{0.006} \mathrm{~S}_{0.012}$ \\
Coal/dry & 0 & 37.4 & 54.3 & 8.3 & 33.25 & 80.36 & 12.17 & 5.08 & 1.45 & 0.94 & $\mathrm{CH}_{0.729} \mathrm{O}_{0.114} \mathrm{~N}_{0.015} \mathrm{~S}_{0.004}$ \\
\hline
\end{tabular}




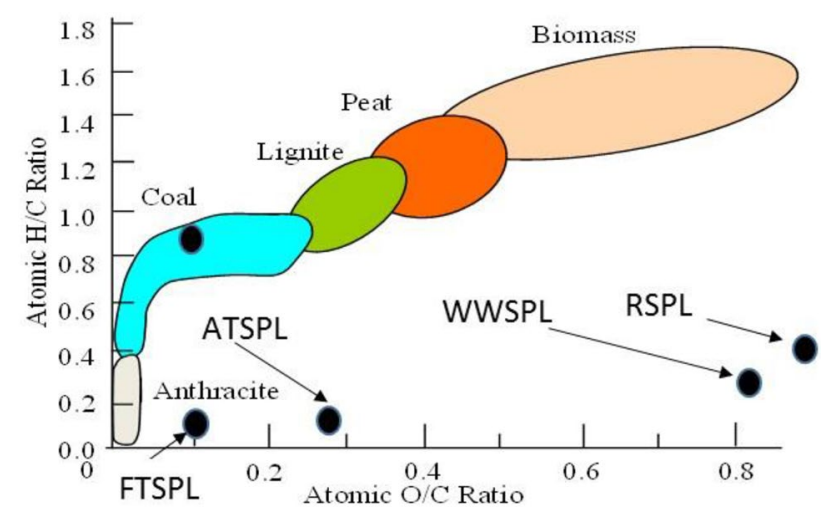

Fig. 3 Van-Krevelen diagram representation and the location of the different types of SPL grades

reach a fine mesh size near $100 \mu \mu$. Bomb calorimetry and XRF analysis typically require sample mass in the order of several grams, while TGA, Elemental Analyzers, and ICP require samples in the order of one-tenth of a gram or smaller. Therefore, sampling and testing following statistical approach to achieve reproducible statistical representation of the SPL composition is always necessary. In this work, four different grades of SPL were presented and these include i) Raw or as received SPL (RSPL), ii) waterwashed SPL (WWSPL), iii) water-washed followed with Acid-Treated SPL (ATSPL), and iv) water-washed SPL followed with two treatments, primary basic with $\mathrm{NaOH}$ and a secondary acidic with $\mathrm{H}_{2} \mathrm{SO}_{4}$ (FTSPL). More details about the SPL compositions and the heating values were given in the previous experimental and modeling studies $[29,43]$.
Table 5 summarizes the proximate and ultimate analyses for the four considered SPL grades and including their measured calorific values and the inferred unit formula. These formulas are also presented on Van-Krevelen diagram as shown in Fig. 3. The SPL treatment appears to have solubilized and removed good portion of the mineral contents of the SPL as noticed by the increasing fraction of the fixed carbon particularly the ATSPL and FTSPL and reaching to near anthracite coal grade as depicted in Fig. 2.

The coal properties were given according to MacPhee [44] of bituminous type and characterized with heating value (LHV) of $32.3 \mathrm{MJ} / \mathrm{kg}$. In general, the SPL is characterized with low volatile fraction and Heating values compared to the baseline bituminous coal.

\subsection{Equilibrium analysis}

The gasification model was validated against a baseline coal stream as depicted in Fig. 4. The coal has a general consensus in the published literature. These results has a best CG efficiency of $77 \%$ at a temperature of $1,300^{\circ} \mathrm{C}$ with corresponding molar fractions for $\mathrm{CO}, \mathrm{H}_{2}$, and $\mathrm{CH}_{4}$ of 0.595 , 0.377 , and 0.007 , respectively, and oxidizer and moderator molar ratio of 1.84 and 1.32. The trends are realistic as the increase in temperature favors the endothermic reactions-steam gasification reaction and Boudouard reaction-and, thus, is in agreement with Le Chatelier Principle. The decrease in $\mathrm{CO}_{2}$ and steam as well as the decrease in methane are in accordance with the same principle. The issue, however, is more with the amount of $\mathrm{CO}_{2}$ and $\mathrm{H}_{2} \mathrm{O}$ which typically co-exist with the syngas at substantial
Fig. 4 Model results for the gasification of the baseline coal

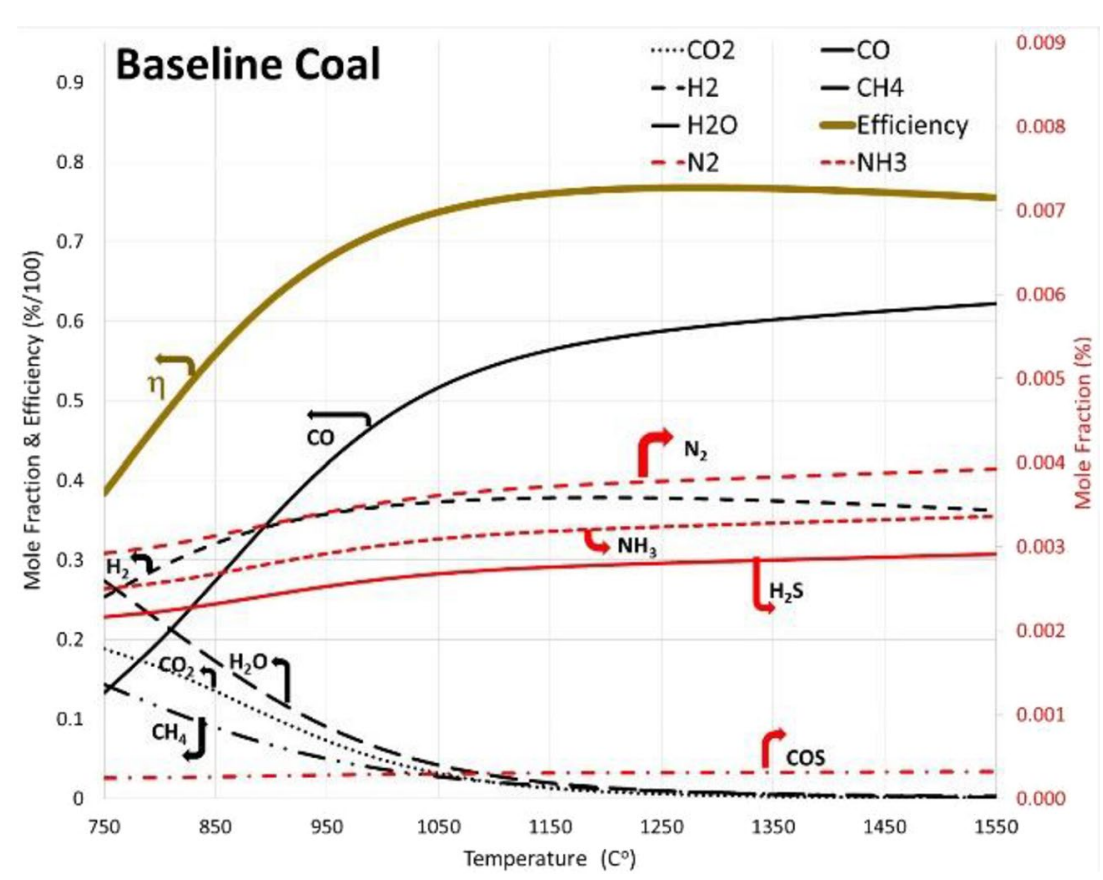

SN Applied Sciences 
Fig. 5 Model results for the gasification of WWSPL

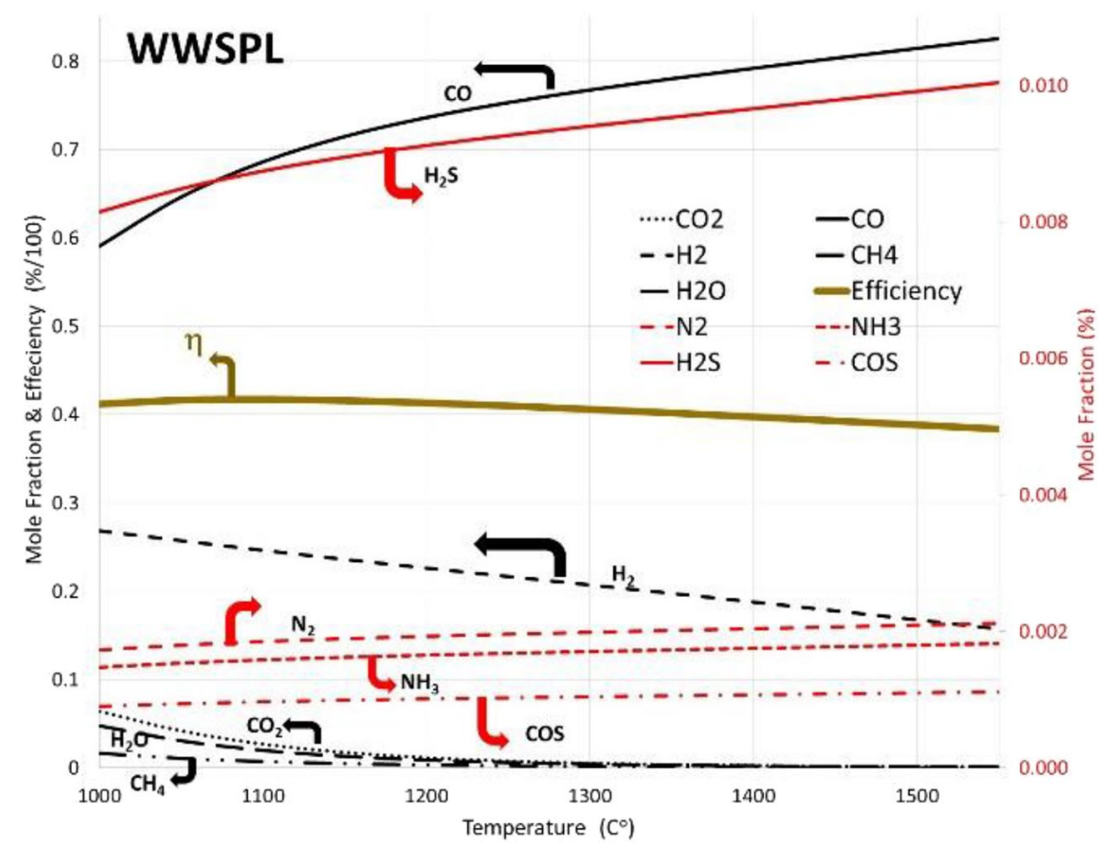

fraction. Abani and Ghoniem [41] have reported the molar fractions of the main gasification species. Despite some of the noticed discrepancies between the reported measurements and numerical simulation, they provided a platform for the resulted species range, i.e., $\mathrm{CO} \approx 0.33, \mathrm{H}_{2} \approx 0.19$, $\mathrm{CO}_{2} \approx 0.18$ and $\mathrm{H}_{2} \mathrm{O} \approx 0.28$. Therefore, the low fidelity analysis is thought to be an idealistic conversion as it lacks any presence of the associated combustion species with the syngas components which is less typical for coal gasification. Moreover, the dimension of the gasifier geometry is neglected in equilibrium which further affects the accuracy of the predictions.

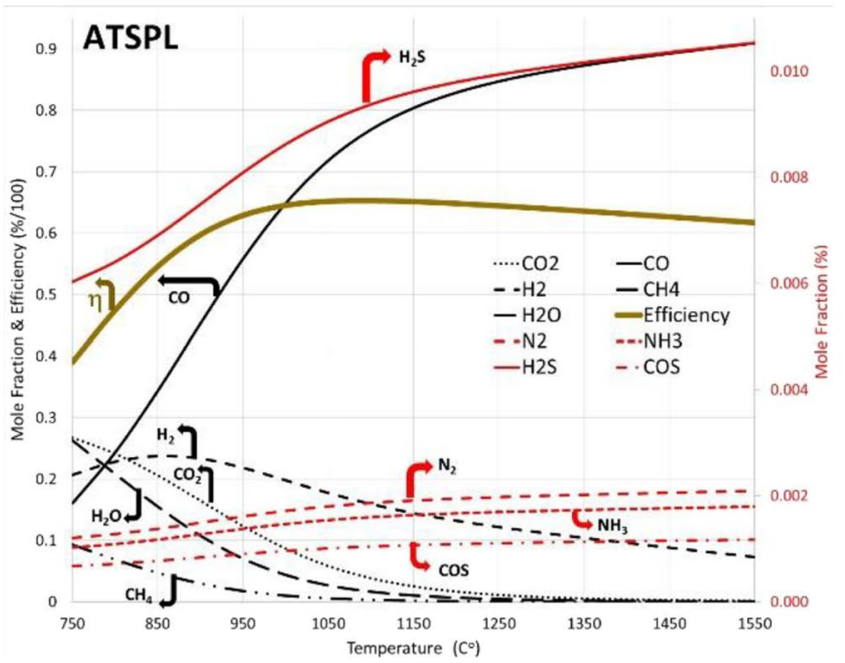

Figure 5 depicts the gasification results for the WWSPL feedstock. It reflects different temperature trends from that described for the coal. Although $\mathrm{CO}$ and $\mathrm{H}_{2}$ dominate the molar fraction, $\mathrm{H}_{2}$ production is on the decline and that led to a very low GE of $39 \%$ and at a rather higher temperature, i.e., $1450{ }^{\circ} \mathrm{C}$. The corresponding molar ratios of the oxidizer and moderators were, respectively, 0.0141 and 0.417 and that corresponds to $\mathrm{X}_{\mathrm{CO}}$ of 0.804 and $\mathrm{X}_{\mathrm{H} 2} 0.178$. Therefore, even though a good syngas fraction was produced, the process seems more of a pyrolysis than a gasification and much of the energy needed in the process led to low GE. This due to the unfit composition of the feedstock with a large fraction of ash based on its proximate

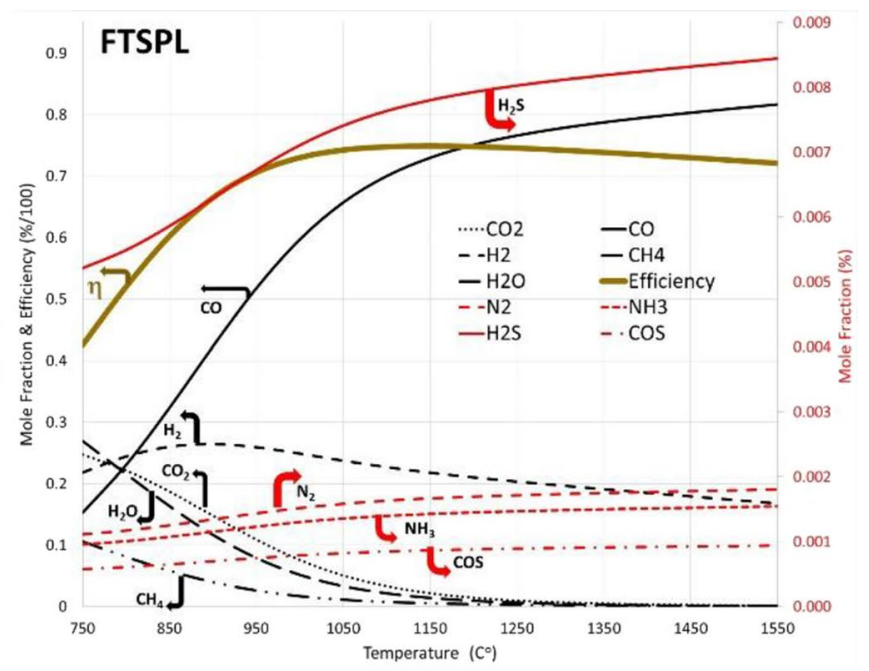

Fig. 6 Model results for the gasification of the treated ATSPL and FTSPL 
Table 6 Summary of the gasification modeling results

\begin{tabular}{lllllll}
\hline Feedstock & GC (\%) & Temperature $\left({ }^{\circ} \mathrm{C}\right)$ & CO mole fraction & $\mathrm{H}_{2}$ mole fraction & $\begin{array}{l}\text { Oxidizer } \\
\text { mole ratio }\end{array}$ & $\begin{array}{l}\text { Moderator } \\
\text { mole ratio }\end{array}$ \\
\hline Coal & 77 & 1,300 & 0.595 & 0.377 & 1.84 & 1.32 \\
WWSPL & 39 & 1,450 & 0.804 & 0.178 & 0.0141 & 0.417 \\
ATSPL & 65 & 1,100 & 0.769 & 0.159 & 1.29 & 1.02 \\
FTSPL & 75 & 1,150 & 0.730 & 0.218 & 1.971 & 1.973 \\
\hline
\end{tabular}

analysis coupled with a very large fraction of oxygen, signifying an oxidized compound that always holds low heating value to be gasified. In addition, it should be noted that lower temperatures $(<1450)$ resulted in negative values for the oxidizer and moderator ratios signifying the inability to gasify the feedstock under this condition, and the unreliability of the model results at these temperatures.

The analysis of the gasification of the treated ATSPL and FTSPL is shown in Fig. 6, and they, respectively, resulted in GE of $65 \%$, and $75 \%$ with corresponding syngas molar fractions $\left(\mathrm{X}_{\mathrm{CO}} \& \mathrm{X}_{\mathrm{H} 2}\right)$ of $0.769 \& 0.159$, and $0.730 \& 0.218$ at temperatures of $1,100^{\circ} \mathrm{C}$, and $1,150{ }^{\circ} \mathrm{C}$. The corresponding oxidizer and moderator mole needed for each mole of ATSPL are 1.29 and 1.02, while for FTSPL, it is 1.971 and 1.973, respectively. The gasification results are summarized in Table 6. Compared to the values for baseline coal, these results suggest the potential and feasibility of gasification of only the fully treated, i.e., FTSPL.

\subsection{High fidelity modeling}

High fidelity results were first shown for the coal as its conversion trends appear in several works including Adeyemi and Janajreh [33], Chen et al. [26, 27], Watanabe and Otaka
[28], Shi et al. [45] and Wu et al. [46] and Adeyemi et al. [40]. A similar trend and comparable values were achieved and with the species distribution as depicted in Fig. 7. The main gasification species compared well with the simulation of Abani and Ghoniem who, respectively, reported 0 . 20 and 0.21 mole fraction for $\mathrm{CO}$ and $\mathrm{H}_{2}$ and compared to 0.178 and 0.23 obtained in this work. Their results and our simulation were in the same trend to experimental measurements of Brown et al. [24] who reported higher $\mathrm{CO}$ and slightly lower $\mathrm{H}_{2}$; discrepancies were attributed to several parameters among those are the mode of introduction of the coal, small mismatch in the temperature, and none uniformity of the species distribution near the gasifier exit. It is also worth noting the co-presence of the combustion species, i.e., $\mathrm{CO}_{2}$ and $\mathrm{H}_{2} \mathrm{O}$ side to the syngas that was not observed in the low fidelity as per the comparison in Fig. 8 (left). Whereas the $\mathrm{H}_{2} \mathrm{O}$ is in favorable comparison with both Abani and Brown et al. [24] work, the $\mathrm{CO}_{2}$ shows some discrepancies. Furthermore, in the study of Gao et al. [12], they showed that the temperature of gasifier increased along the reactor for both high volatile coal and washed SPL. This trend shows similarity to what was obtained in our study.

In view of these agreeable syngas results for the coal, the gasification of the FTSPL is presented in Fig. 8. The


Fig. 7 High fidelity model results and comparison with experimental and literature work of the baseline coal gasification. (Left) species distribution along the centerline line, (right) comparison of the current models with literature model and experimental results 

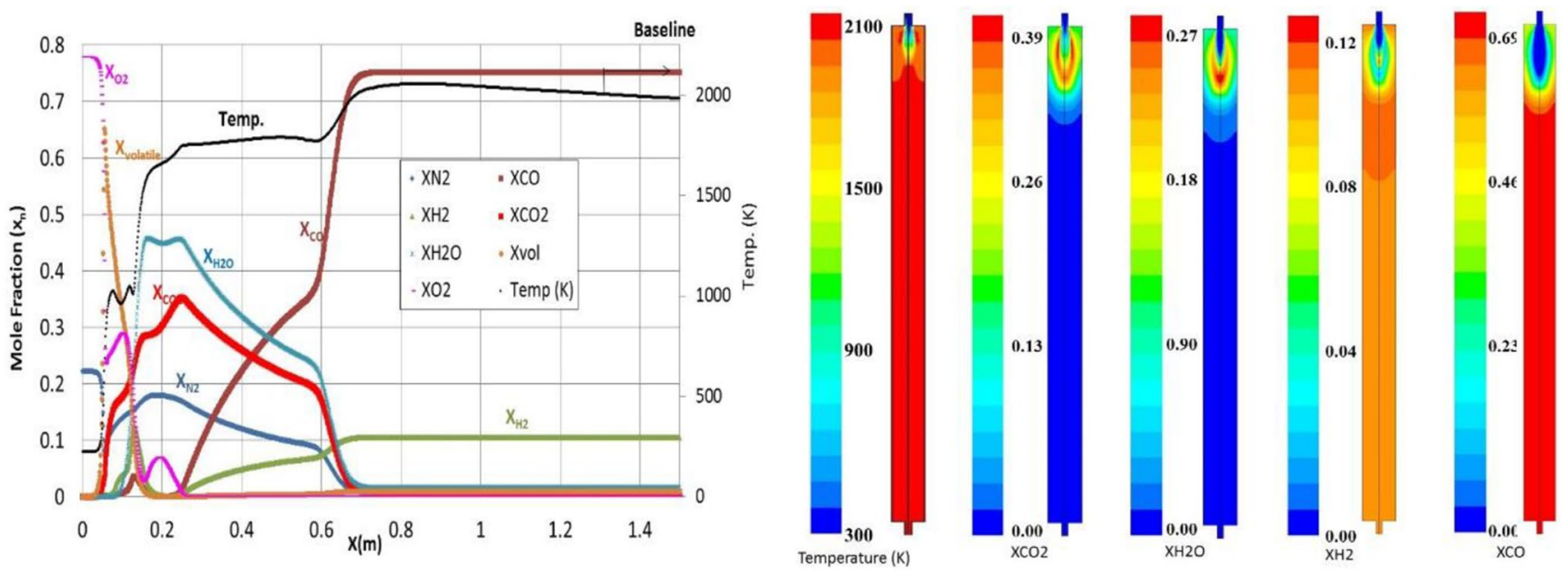

Fig. 8 depicts results of the mole fractions of the FTSPL gasified species and temperature: left) along the centerline, right) contour distributions in the axi-symmetrical slice

gasification species distribution along the centerline (Fig. 8 left) for the FTSPL depicts different characteristics from the coal. Firstly, it shows a time delay in the combustion species of the injected FTSPL to appear upstream alongside with the syngas. This is mainly due to the very low volatile fraction beside the higher ash contents that preclude a quick ignition or gasification of the feedstock compared to coal. Ignition of the FTSP is implemented by imposing and batching the gasifier with a high initial temperature of $2227^{\circ} \mathrm{C}$ that provide the needed temperature source to de-moisturize and devolatile as well as in transmitting the required needed heat to start the ignition of FTSPL particles. Therefore, as the particle temperature is raised beyond the ignition temperature for the char, the onset of partial combustion takes place. This stage of the process, however, is controlled by the amount/ratio of the introduced oxidizer as was calculated according to the gasification stoichiometry to avoid rich air and complete combustion or very lean air and none sustainable partial combustion. Accordingly, the temperatures reach to their steady state and the partial combustion become responsible for maintaining the gasifier temperature. The process also entails $\mathrm{CO}_{2}$ (as well as $\mathrm{H}_{2} \mathrm{O}$ based on the available volatile amount) reduction and gasification that seems to take place concurrently per the reactions listed in Table 4. This also encompasses short endothermic activities that require some heat to liberate the limited volatile fraction, its fractioning per reaction (R8), and the gas shift (R3 and R7) gasification reactions. Nevertheless, the temperature stabilizes and reaches near an asymptotic value leading
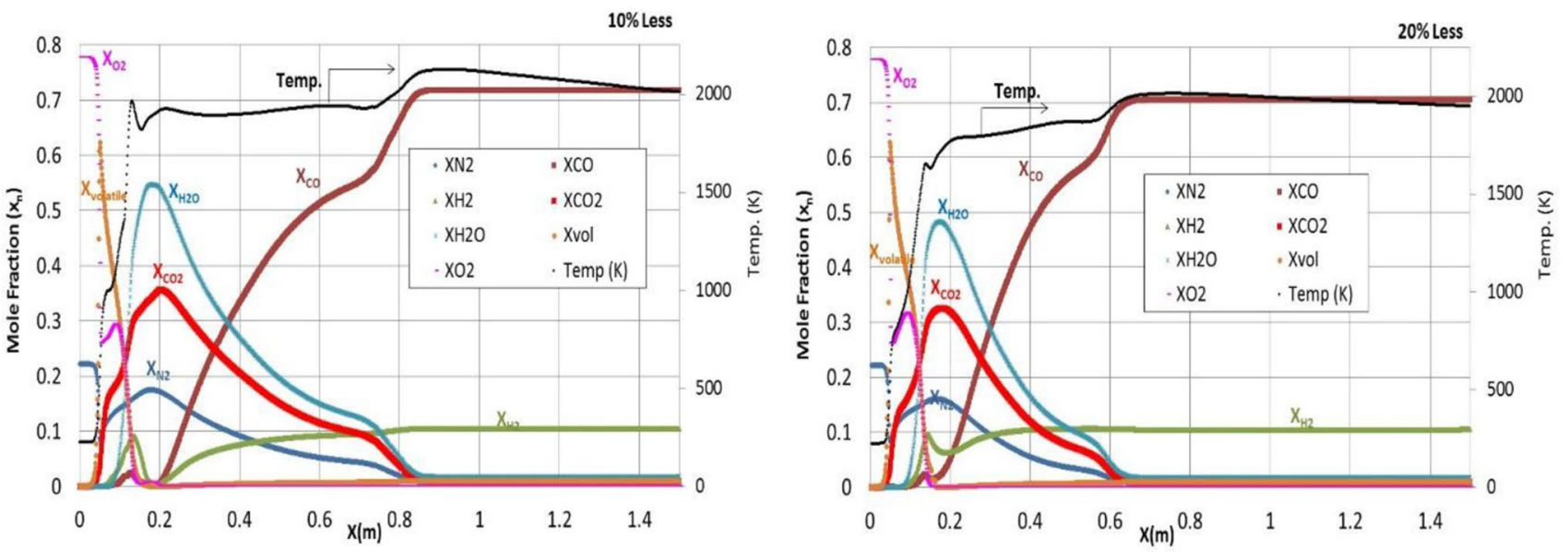

Fig. 9 depicts results of the mole fractions of the FTSPL gasified species and temperature along the centerline and at a lower baseline oxidizer values 
also to a consistent syngas yield and combustion components values prior to reaching midstream of the gasifier. The process is clearly presented in Fig. 8, such that devolatilization species evolves first and is then followed by the combustion species which results in quick rise in the temperature and molar values of $\mathrm{H}_{2} \mathrm{O}$ and $\mathrm{CO}_{2}$ near 0.45 and 0.35 , respectively. Gasification utilizes the remaining oxidizer and the high reached temperature, and thereafter, commence the conversion of the larger remaining dry and moisture free (fixed carbon) fraction of the FTSPL.

Secondly, the syngas molar fraction reaches 0.75 and 0.10 for $\mathrm{CO}$ and $\mathrm{H}_{2}$, respectively. A much lower combustion components value of 0.01 and 0.02 for each of $\mathrm{H}_{2} \mathrm{O}$ and $\mathrm{CO}_{2}$ was observed at the exit of the gasifier. This suggests the reduction was complete before reaching the gasifier exit as indicated by the low molar fraction distribution in Fig. 9. One can also notice that the $\mathrm{CO}$ molar fraction component of the syngas for the FTSPL is at a much higher value than what have been evaluated for the coal, but contrarily for $\mathrm{H}_{2}$ components. This is in line with their proximate and elemental composition for FTSPL that neither hold a substantial fraction of the moisture nor of volatile which are considered the source of $\mathrm{H}_{2}$. Thirdly, a high gasification temperature of the gasifier was necessary also to ensure near complete conversion of the char component of the FTSPL. As a lower initial temperature was attempted, but it leads to far from complete conversion and consequent drastic reduction in the gasification efficiency. Therefore, the gasifier temperature is one of the main parameter to keep in mind in order to achieve complete conversion and gasification of the FTSPL. This temperature is controlled by the ratio of the injected feedstock (FTSPL) to that of the Oxidizer stream.

In the high fidelity simulation, the oxidizer was represented as a mixture of $\mathrm{O} 2$ and $\mathrm{N} 2$ at 8:2 molar ratio, which simulated the air. Accordingly, as a higher temperature was required to ensure complete conversion, a lower cold gasification efficiency for the FTSPL was anticipated due to the higher attained sensible heat that was mainly consumed by the larger ash fraction without contributing any heat of reaction to the reactor. The result of the CGE was nearly $70 \%$ for the FTSPL vs $77 \%$ for the coal. This efficiency is based on the heating value ratio of the accumulative syngas to that of feedstock, i.e., FTSPL or coal. The gasification species distributions showed a uniform presence from midstream and down to the gasifier exit suggesting less spatial and temporal dependency of the process on the reactor geometry. This reinforced the benefits of the utilization of sufficiently long reactor size such as the one used in this case (i.e., $L=1.53 \mathrm{~m}$ ). Hence, it bolstered the gasification process by providing necessary time that resulted in stable and steady solution. It should be noted that the non-uniformly varying solution of the species upstream emphasized the importance of high fidelity. On the other hand, it highlighted the shortcomings of the equilibrium system based on low fidelity modeling as regards the physical capturing of the exact process behavior.

\subsubsection{Sensitivity of the flow rate}

The main goal in gasification is generally to attain optimal conversion metrics, i.e., near $100 \%$ conversion ratio, highest cold gasification efficiency (CGE), and the desired proportion of the molar fraction of the syngas species. To achieve this goal, a sensitivity study is attempted initially to increase the throughput at the corresponding oxidizer values. The results are summarized in Table 7 in the form of conversion percentile, absorbed latent heat for the release of the moisture, sensible heat that is utilized by the introduced mass flow of the FTSPL, and finally the released heat in the form of heat of the reactions. Both the sensible and latent heat are directly proportional to the injected FTSPL due to the high attained temperature of the gasifier that is beyond the evaporation temperature of the moisture contents embedded in the feedstock/FTSPL. The sensible heat, which is the heat responsible of elevating the feedstock from the entry temperature values to the attained exit gasifier temperature, would depend on the yield components and their corresponding specific heats along with the exit

Table 7 Summary of the conversion at different throughput ratio and gasification stoichiometric conditions

\begin{tabular}{|c|c|c|c|c|c|c|c|c|}
\hline Condition & Mass flow (kg/s) & Conversion (\%) & Incomplete (\%) & $\begin{array}{l}\text { Latent heat } \\
\text { (Watt) }\end{array}$ & $\begin{array}{l}\text { Sensible heat } \\
\text { (Watt) }\end{array}$ & $\begin{array}{l}\text { Reaction heat } \\
\text { (Watt) }\end{array}$ & $\begin{array}{l}\text { Reactor } \\
\text { energy (MJ/ } \\
\text { kg) }\end{array}$ & $\overline{\text { CGE (\%) }}$ \\
\hline Baseline & 0.00563 & 99.10 & 0.90 & 267.30 & $19,089.94$ & $110,478.86$ & 19.62 & 70.0 \\
\hline$-10 \%$ & 0.00507 & 98.50 & 2.70 & 240.57 & $16,720.63$ & $99,183.80$ & 19.57 & 69.9 \\
\hline$-20 \%$ & 0.00451 & 96.50 & 4.50 & 213.84 & $14,434.34$ & $86,495.59$ & 19.20 & 68.5 \\
\hline$+10 \%$ & 0.00620 & 86.50 & 14.50 & 294.03 & $18,843.83$ & $105,523.13$ & 17.03 & 60.3 \\
\hline$+20 \%$ & 0.00676 & 80.10 & 19.90 & 320.76 & $18,927.62$ & $106,683.47$ & 15.79 & 56.3 \\
\hline
\end{tabular}


gasifier temperature. Thus, the sensible heat is a variable with many parameters and can go either up or down with the increase in throughput. Similarly, the heat of reaction, which depends on the conversion rate and how the reaction swings in producing syngas or combustion species or their combinations. The heat of reaction together with the conversion rate indicates the suitable feedstock mass flow rate and reactor capacity. Results of increasing or decreasing the throughput from the baseline value have failed to augment the conversion of the char per the obtained results in Table 7 and suggesting the baseline mass flux is the most fitted value. The reactor energy signifies the portion of energy actually converted into syngas, and it appears the best value of $19.62 \mathrm{MJ} / \mathrm{kg}$ was obtained at the baseline mass flow rate of $0.005636 \mathrm{~kg} / \mathrm{s}$ compared to lower and higher throughput of $\pm 20 \%$ that marked 19.20 and $15.79 \mathrm{MJ} / \mathrm{kg}$, respectively. The best achieved CGE is $70 \%$ at the baseline condition, and it reduces as one increases or decreases the injection FTSPL and associated oxidizer values.

Therefore, a higher injection rate (throughput) not only leads to drastic reduction in the conversion of the injected FTSPL particles, but consequently also to lower reaction heat that greatly penalized the CGE.

\subsubsection{Sensitivity of the oxidizer}

The role of the oxidizer amount per the results species distributions was studied as depicted in Fig. 9 at lower and Fig. 10 at higher oxidizer conditions and is summarized in Table 8. The results showed a reduction in $\mathrm{CO}$ syngas component, but with unnoticeable decrease in $\mathrm{H}_{2}$ component. The reason is because volatile conversion goes into completion under all attempted conditions. Consequently, the volatile was less sensitive to the considered oxidizer amount compared to the char conversion which is considered the limiting reaction rate in Figs. 9 and 10. The low attained value of $\mathrm{CO}$ molar fraction at 10 and $20 \%$ lean oxidizer conditions is due to low conversion of the char which was nearly $96.5 \%$ and $94.2 \%$, respectively, compared to the $99.1 \%$ that was observed at the baseline. At richer oxidizer condition, the molar fraction of $\mathrm{CO}$ drops. This is due to production of higher molar fraction of the combustion species as depicted in Table 4. For example, at $+10 \%$ reaches 0.01904 for $X_{\mathrm{H} 2 \mathrm{O}}$ and 0.01155 for $X_{\mathrm{CO}_{2}}$ while at $+20 \%$ reaches 0.2517 for $X_{\mathrm{H} 2 \mathrm{O}}$ and 0.5622 for $X_{\mathrm{CO}_{2}}$. The increase in the oxidizer at $+10 \%$ condition results in a relatively comparable result to that of the baseline $X_{\mathrm{H} 2 \mathrm{O}}$ of 0.01629 and $\mathrm{X}_{\mathrm{CO} 2}$ of
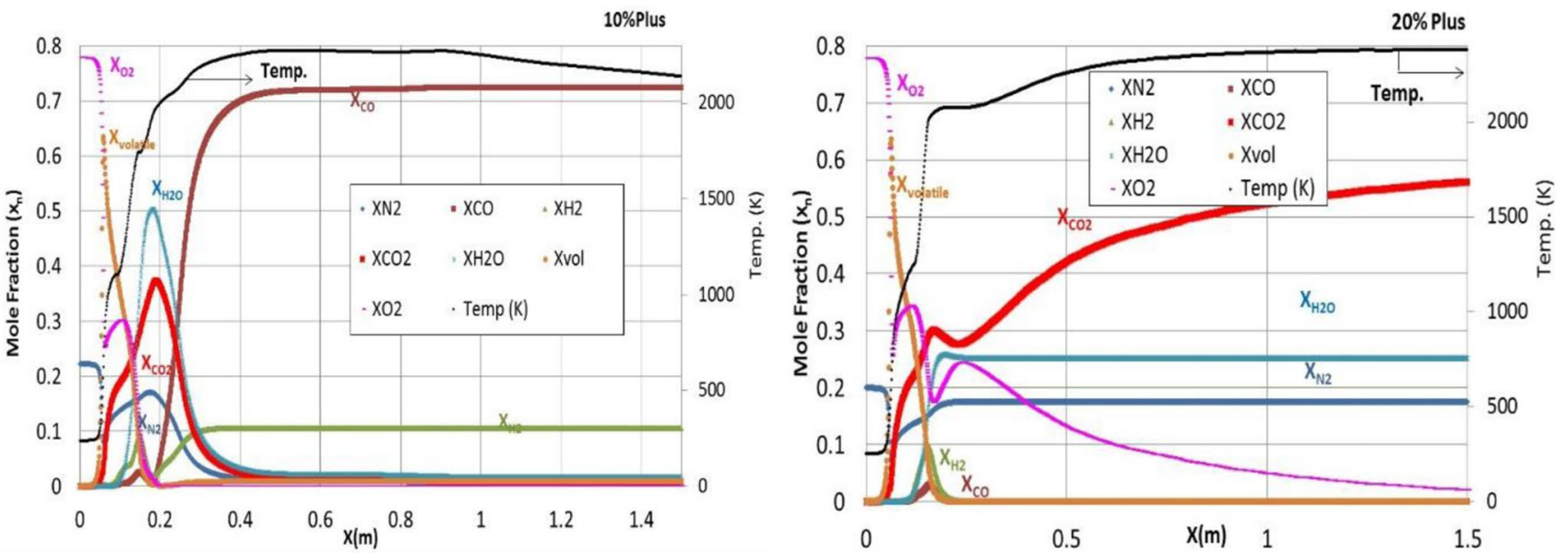

Fig. 10 depicts results of the mole fractions of the FTSPL gasified species and temperature along the centerline and at a higher baseline oxidizer values

Table 8 Species distribution and conversion at the exit of the gasifier at different oxidizer ratio

\begin{tabular}{llllllll}
\hline Oxidizer & $\mathrm{CO}_{2}$ (mole fraction) & $\mathrm{H}_{2} \mathrm{O}$ (mole fraction) & $\mathrm{CO}$ (mole fraction) & $\mathrm{H}_{2}$ (mole fraction) & Temp. $\left({ }^{\circ} \mathrm{C}\right)$ & Conv. \% & $\mathrm{CGE}(\%)$ \\
\hline Baseline & 0.00837 & 0.01629 & 0.75158 & 0.10487 & 1751 & 99.1 & 70.1 \\
$-10 \%$ & 0.00935 & 0.01804 & 0.71815 & 0.10491 & 1706 & 96.5 & 67.4 \\
$-20 \%$ & 0.00904 & 0.01762 & 0.70518 & 0.10451 & 1658 & 94.2 & 61.1 \\
$+10 \%$ & 0.01155 & 0.01904 & 0.69324 & 0.10041 & 1832 & 99.89 & 66.5 \\
$+20 \%$ & 0.5622 & 0.2517 & 0.00000 & 0.00000 & 2106 & 100 & 0 \\
\hline
\end{tabular}


0.00837 , whereas at a higher increase of $+20 \%$ oxidizer the gasification goes into complete combustion instead. It results in a nil value of syngas fraction, nevertheless a $100 \%$ conversion was reached in the form of combustion. Temperature of the gasifier seems also directly proportional to the increase in the gasifier oxidizer amount. For example, at the baseline it marked $1751^{\circ} \mathrm{C}$ and by lowering by $10 \%$ and $20 \%$, it lead to decrease in temperature which reached 1706 and $1658^{\circ} \mathrm{C}$, respectively. Conversely, when increased by $10 \%$ and $20 \%$ the decrease in temperature was marked to reach 1832 and $2106^{\circ} \mathrm{C}$, respectively. The latter higher temperatures suggest the undergoing combustion instead of gasification, particularly at $+20 \%$ oxidation case which lead to complete combustion instead and a nil value of CGE.

\section{Conclusion}

Aluminum industry produces an alarming and increasing amount of hazardous, non-recyclable, solid waste known as spent pot lining that grew to $1 \mathrm{Mt}$ annually. This waste can be sorted into two cuts with one being carbonaceous and the other inorganic. In this work, the technical feasibility of gasification of SPL of different level of treatment was evaluated through equilibrium modeling. The model considered 11 species including the molar ratio of the moderator steam $\left(\mathrm{H}_{2} \mathrm{O}\right)$ and the oxidizer $\left(\mathrm{O}_{2}\right)$ in addition to the molar fractions of $\mathrm{CO}, \mathrm{H}_{2}, \mathrm{CH}_{4}, \mathrm{~N}_{2}$, $\mathrm{NH}_{3}, \mathrm{H}_{2} \mathrm{~S}, \mathrm{COS}, \mathrm{H}_{2} \mathrm{O}$, and ash. The process metrics were assessed via the produced syngas fraction ( $\mathrm{CO}$ and $\mathrm{H}_{2}$ ), gasification efficiency (GE), and in comparison with the gasification of a baseline bituminous coal. The gasification model was validated against a baseline coal stream which has a general consensus in previous reports, i.e., near $77 \% \mathrm{GE}$ and molar fractions for $\mathrm{CO}, \mathrm{H}_{2}$ and $\mathrm{CH}_{4}$ of $0.595,0.377$, and 0.007 , respectively at a temperature of $1300{ }^{\circ} \mathrm{C}$ and moderator mole of 1.84 and oxidizer mole of 1.32. The SPL results for each of the WWSPL, ATSPL, FTSPL, respectively, showed a GE of 40,65 , and $75 \%$ with corresponding syngas ( $\mathrm{CO}$ and $\mathrm{H}_{2}$ ) molar fractions of 0.804 and $0.178,0.769$ and 0.159 , and 0.730 and 0.218 at temperatures of 1450,1100 , and $1150^{\circ} \mathrm{C}$, respectively. These results suggest the potential and feasibility of gasification of only the treated SPL. Subsequently, the high fidelity gasification was modeled. The results provided a best CGE of around 70\% for the FTSPL. The molar fraction distribution for the FTSPL is unlike the conventional values for coal and they marked near 0.75 for $\mathrm{CO}$ and 0.1 for $\mathrm{H}_{2}$ with a small fraction for each of $\mathrm{CO}_{2}$ and $\mathrm{H}_{2} \mathrm{O}$ of almost 0.1 . Of the two gasification models studied, the high fidelity model would be recommended because it considers the kinetics, localized flow turbulence and spatial-temporal variations of the species distribution. Consequently, the high fidelity model captured the syngas components at an acceptable level in comparison with the experimental data. However, the low fidelity was further away in its prediction of the values of the main gasification components. This is due to the absence of the concept of time, mixing and geometry in the equilibrium model.

Acknowledgments The support of Khalifa University of Science and Technology (KUST) is highly acknowledged. The technical support also from Egypt Solid Waste Management Center of Excellence at Ain Shams University is acknowledged.

\section{Declarations}

Conflict of interest The authors declare that they have no conflict of interest and this work is solely the work of the authors.

Open Access This article is licensed under a Creative Commons Attribution 4.0 International License, which permits use, sharing, adaptation, distribution and reproduction in any medium or format, as long as you give appropriate credit to the original author(s) and the source, provide a link to the Creative Commons licence, and indicate if changes were made. The images or other third party material in this article are included in the article's Creative Commons licence, unless indicated otherwise in a credit line to the material. If material is not included in the article's Creative Commons licence and your intended use is not permitted by statutory regulation or exceeds the permitted use, you will need to obtain permission directly from the copyright holder. To view a copy of this licence, visit http://creativecommons .org/licenses/by/4.0/.

\section{References}

1. Chanania F, Eby E (2000) Best demonstrated available technology (BDAT) background document for spent aluminum potliners-D088. Environmental Protection Agency (EPA), 53 Fed. Reg. 3541240 C.F.R.; Part 261: 35411-35421

2. Rustad I, Karstensen KH, Ødegrd KE (2000) Disposal options for spent potlining. In: Waste management series, vol 1. Elsevier, New York, pp. 617-632

3. Chen X (2011) Latest status of processing technologies for spent potlining from aluminum smelters. Light Metals 12:21-25

4. Haiying L, Jinling W, Shifu S, Youfa L (2012) Study on process mineralogy of a used cathode of carbon block from electrolytic aluminum factory. Proced Environ Sci 16:749-757

5. Gunasegaram DR, Molennar D (2015) Towards improved energy efficiency in the electrical connections of Hall-Héroult cellsthrough finite element analysis (FEA) modeling. J Clean Prod 93:174-192

6. George H, Raymond B (2013) An overview of useful methods to treat, recover, or recycle spent potlining. JOM 65:1441-1451

7. Regain Processing Technology. http://www.regainmaterials .com/aluminium-smeltingindustry/regain-spl-solution/splprocessing-technology. Accessed 8 August 2017

8. Harald $A \varnothing$ (2017) Discussion of industrial spent pot lining treatment, Travaux 46. In: Proceedings of 35th international ICSOBA conference, Hamburg, Germany 
9. Venâncio LCA, Souza JAS, Macedo EN, Nazareno J, QuaresmaN PAEM (2010) Residues recycling: reducing costs and helping the environment. JOM 62(9):41-45

10. Gomes V, Drumond PZ, Neto JOP, Lira AR (2013) Co-processing at cement plant of spent potlining from aluminum industry. In: Tomsett A, Johnson J (eds) Essential readings in lightmetals: electrode technology for aluminum production (4). Wiley, Hoboken, pp 1057-1063

11. Renó MLG, Torres FM, Silva RJ, Santos JJCS, Melo MLNM (2013) Exergy analyses in cement production applying waste fuel and mineralizer. Energy Convers Manag 75:98-104

12. Gao L, Mostaghel S, Ray S, Chattopadyay K (2016) Using SPL (Spent Pot-Lining) as an alternative fuel in metallurgical furnaces. Metall Mater Trans E 3(3):179-188

13. Von Krüger $P$ (2011) Use of spent potlining (SPL) in ferro silicomanganese smelting. In: Lindsay SJ (ed) Light metals. Wiley, Hoboken, pp 275-280

14. Shi Z, Li W, Hu X, Ren B, Gao B, Wang Z (2012) Recovery of carbon and cryolite from spent pot lining of aluminum reduction cells by chemical leaching. Trans Nonferrous Met Soc China 22:222-227

15. Tetronics website: http://tetronics.com/our-solutions/hazar dous-materialtreatment/spent-potliner/. Accessed 7 August 2017

16. Janajreh I, Adeyemi I, Elagroudy S (2020) Gasification feasibility of polyethylene, polypropylene, polystyrene waste and their mixture: Experimental studies and modeling. Sust Energy Technol Assess 39:100684

17. Higman C, Van der Burgt M (2011) Gasification. Gulf Professional Publishing, Oxford

18. Bouraoui Z, Jeguirim M, Guizani C, Limousy L, Dupont C, Gadiou $R$ (2015) Thermogravimetric study on the influence of structural, textural and chemical properties of biomass chars on $\mathrm{CO} 2$ gasification reactivity. Energy 88:703-710

19. Wei J, Song X, Guo Q, Ding L, Yoshikawa K, Yu G (2019) Reactivity, synergy, and kinetics analysis of $\mathrm{CO} 2$ co-pyrolysis/co-gasification of biomass after hydrothermal treatment and coal blends. Energy Fuels 34(1):294-303

20. Wei J, Ding L, Gong Y, Guo Q, Wang Y, Yu G (2020) High-temperature char gasification of anthracite/petroleum coke: using biomass leachate as cheap-effective additive. Asia-Pac J Chem Eng 15(4):e2454

21. Basu P (2010) Biomass gasification and pyrolysis: practical design and theory. Academic Press, New York

22. Mazzoni L, Janajreh I, Elagroudy S, Ghenai C (2020) Modeling of plasma and entrained flow co-gasification of MSW and petroleum sludge. Energy 196:117001

23. Sreedharan V (2012) CFD Analysis of Coal and Heavy Oil Gasification for Syngas Production. Aalborg University, Aalborg

24. Brown BW, Smooth LD, Smith PJ, Hedman PO (1988) Measurement and prediction of entrained flow coal gasification processes. AICHE J 34:435-446

25. Hill SC, Smooth LD (1993) A comprehensive three-dimensional model for simulation of combustion systems, PCGC-3. Energy Fuel 7:874-883

26. Chen C, Horio M, Kojima T (2000) Numerical simulation of entrained flow coal gasifiers. Part I: modeling of coal gasification in an entrained flow gasifier. Chem Eng Sci 55(18):3861-3874

27. Chen C, Horio M, Kojima T (2000) Numerical simulation of entrained flow coal gasifiers. Part II: effects of operating conditions on gasifier performance. Chem Eng Sci 55(18):3875-3883

28. Watanabe H, Otaka M (2006) Numerical simulation of coal gasification in entrained flow coal gasifier. Fuel 85(12-13):1935-1943

29. Ghenai C, Inayat A, Shanableh A, Sarairah Al, Janajreh I (2019) Combustion and emissions analysis of spent pot lining (SPL) as alternative fuel in cement industry. Sci of Tot Enviorn 684:519-526

30. Shabbar S, Janajreh I (2013) Thermodynamic equilibrium analysis of coal gasification using Gibbs energy minimization method. Energy Convers Manag 65:755-763

31. Talab I, Al-Nahari Z, Qudaih R, Janajreh I (2010) Numerical modeling of coal tire-shred co-gasification. JJMIE 4(1):155-162

32. Adeyemi I, Janajreh I (2012) Modeling of the entrained flow gasification: kinetics-based ASPEN Plus model. Renew Energy 82:77-84

33. Adeyemi I, Janajreh I (2014) Detailed kinetics-based entrained flow gasification modeling of Utah bituminous coal and waste construction wood using aspen plus. In: Hamdan M, Hejaze $\mathrm{H}$, Noura H, Fardoun A (eds) Conference, ICREGA14, the 3rd Int. Conf. on Rewable Engergy Generation and Application, Al-Ain, UAE, Volume: Springer Book, pp 59-71. https://doi. org/10.1007/978-3-319-05708-8_49

34. Wang Z, Yang J, Li Z, Xiang Y (2009) Syngas composition study. Front Energy Power Eng Chin 3(3):369-372

35. Jarungthammachote $S$, Dutta A (2008) Equilibrium modeling of gasification: Gibbs free energy minimization approach and its application to spouted bed andspout-fluid bed gasifiers. Energy Convers Manag 49(6):1345-1356

36. Jarungthammachote S, Dutta A (2007) Thermodynamic equilibrium model and second law analysis of a downdraft waste gasifier. Energy 32(9):1660-1669

37. Prins MJ, Ptasinski KJ, Janssen FJJG (2007) From coal to biomass gasification: Comparison of thermodynamic efficiency. Energy 32(7):1248-1259

38. de Souza-Santos ML (2004) Solid fuels combustion and gasification: modeling, simulation, and equipment operation, Mechanical engineering, vol 180. Marcel Dekker, New York, p 439

39. Almazrouei M, Janajreh I (2020) Model-fitting approach to kinetic analysis of non-isothermal pyrolysis of pure and crude glycerol. Renewable Energy 145:1693-1708

40. Adeyemi I, Janajreh I, Arink T, Ghenai C (2017) Gasification behavior of coal and woody biomass: validation and parametrical study. Appl Energy 185:1007-1018

41. Abani N, Ghoniem A (2013) Large eddy simulation of coal gasification in an entrained flow gasifier. Fuel 104:6640680

42. Kumar M, Ghoniem AF (2011) Multiphysics simulations of entrained flow gasification, Part II: Constructing and validating the overall model. Energy Fuels 26(1):464-479

43. Indurkar PD (2014) Optimization in the treatment of spent pot lining - a hazardous waste made safe. MTech thesis., EThesis @ NIT Rourkela Biju Pantnaik Central Library, National Institute of Technology, Rourkala, Odisha. http://ethesis.nitrkl.ac.in/6222/

44. Macphee J E, Sellier M, Jermy M, Tadulan E (2009) CFD modeling of pulverized coal combustion in rotary lime kiln. In: 7th Int. conference on CFD in minerals and process industries, CSIRO Melbourne, Australia

45. Shi SP, Zitney SE, Shahnam M, Syamlal M, Rogers WA (2006) Modelling coal gasification with CFD and discrete phase method. J Energy Inst 79(4):217-221

46. Wu Y, Zhang J, Smith PJ, Zhang H, Reid C, Lv J, Yue G (2010) Three-dimensional simulation for an entrained flow coal slurry gasifier. Energy Fuels 24(2):1156-1163

47. Janajreh I, Shabbar S, Elagroudy S (2015) Co-firing of Enteromorpha prolifera algae and rtc coal in a down draft gasifier: material characterization and flow simulation. J Solid Waste Tech Manag 41(1):68-83

Publisher's Note Springer Nature remains neutral with regard to jurisdictional claims in published maps and institutional affiliations. 